\title{
A CRITICAL THOUGHT OF INSTRUCTIONAL STRATEGY: DEVELOPING ANALYTICAL CAPABILITY OF AUTOMOTIVE STUDENTS BY MANAGING MORE APPLICABLE MOVIE FRAGMENTS, POWER POINT, AND INTERACTIVE TEST
}

\author{
Agus Riyanto \\ A Teacher of Light Vehicle Technique at SMK IB Khalifah Bangsa Metro Who Have Been Teaching \\ Automotive For 20 Years In Various Technical High School
}

\begin{abstract}
What most sensed about Technical High School (known as SMK) students is their lack of analytical capability. As their nature of academic orientation is aimed at job fullfillment, the students are enhanced to follow Standard Operational Procedure (SOP) without questioning why such SOP should be followed. As for automotive students, they simply following the steps of doing things related to any activities of repairing car and other mechanical work required just because the job will be done well when the procedure completed.

This kind of mentality "following order or SOP" fits to those who only want to be workers not the men who take higher responsibilities. The progress of automotive technology demand on understanding the concept of how some system used in a car. Failure to comprehend to concept will jeopardize the performance of a car. At the same time, the progress of automotive technology is also propelled by the progress of information technology which provides more open resources that can be used to promote the quality of instuctional process.

Realizing that having analysis compentence is terribly important to run higher responsibilites and continuing education to a university, automotive students need to learn how to analyze. To promote this, teacher can use some automotive movies or animations and then chop them into many fragments related to instructional objectives. The way how the teachers arrange and present the fragments can be combined into power point and ended up with an interactive test with different model of methods, strategies, or techniques. Movies, movie cutter application, interactive test Creator, paint into fragments can be obtained freely from the internet.

The using of movie fragments integrated into power point, arrange the fragment into various strategies, ended up with interactive test will likely focus the students into more realistic understanding toward the concept taught in the classroom. In return the students will be accustomed to analyze each fragment to building comprehension of concept underlying the skill required in automotive work.
\end{abstract}

Key Words: Automotive Students, Movie Fragment, Movie Cutter, Power Point, Paint, Interactive Test Creator, Instructional Strategies

\section{A. Introduction}

Learning achievement has always been becoming a dinamics issue as the effort of improvement keeps changing to facing more challenges. The changing of curriculum proves that learning achievement made by previous ones has not yet reached the satisfaction of three domains "Cognitive, Psycomo-toric, and Afective". Many students got high score but they are lack of good character, they can't even understand how could they get the score since they felt that they didn't study hard. Teachers are demanded and made to expose good achievement of the students by the system. The application of Minimum Passing Grade (known as $\mathrm{KKM})$ in each subjects often neglec-ting the process and circumcising of students'potential to do more in learning.

SMK students suffer most from this situation. They mostly leaded to learn how to achieve psycomotoric domain rather than the other two domains. In automotive vocation, the accentuation of psycomotoric domain exist due to the implementation of SOP during repairing exercise to acquisite the auto-motive competence. This is obvious when the 
nature of SMK edu-cation is to fill job vacancies. Admitted or not, this notion has brought the tea-chers to neglect deep cognitive skill achievement such as analysis capaility. Having the thought that psycomotoric domain is more important than other two domains, teachers are lack of implementing various strategies to promote analysis capability.

There are various kind of instructional strategies. Once it was said by our maestro of education, Dewantara, (1977:28) there are many ways of instructional, but basically they can be divided as follows: 1) voorbeld (demonstrating or exposing sample); 2) gewoontevorming (habituation); 3) leering (teaching); 4) regeering en tucht (instruction, forcing, and punishment; 5) zelfbeheersching, zelf discipline (self behaviour, self discipline); 6) beleving, (experiencing both physics and soul). Almost all the instrutional strategies above have been applied by vocational teachers. Yet the students achievement remains unsatisfaction in term of anaylisis capability. As the progress of information technology rapidly overgrowing the teachers competence, these six basic instructio-nal strategies proposed by Dewantara are less effective when current instructional process fail to associate them with the existence of information technology.

Learning happens to everyone. Learn-ing occurs when experience cause a relatively permanent change in indivi-dual's knowledge or behavior.. To qua-lify as learning, this change must be brought about by experience-by the interaction of a person with his or her environment (Woolfolk, 2004:198). The word environment can be accomo-dated as an instructional condition orchestrated by teachers in a systematic ways. It is so because instructional activities cover many components and then so called as an instructional sys-tem. One of the components is instruc-tional media. The implemention of well organized media will promote learning optimally and lead to the succesfullness of achieving the highest level of each learning domain.

Instructional media used to teaching automotive students in order to achieve anaylisis capability should be attractive in term of focusing their attention as learning progress. As the students learn, they will likely to operate all their senses as an attempt to compre-hend the concept or meaning conveyed during instructional delivery. To do so, the media must catch their eyes, ear, mind, and emotion. Internet provides free movies in many extension, movie cutter, quiz maker, while Microsoft Office provides many fitures such power point and paint which can be used to help building the media. It is okay to build protoype media using the those application but then some revi-sion can be done later as Dick and Carey, 2005:238) say that if one made open selections of media formats and ideal delivery system, however, the likelihood is high that spesifications will be revised during materials deve-lopment process.

The notion of this article is to provide some deep thoughts related to some efforts necessary to create an instructional system by taking advantage of many open resources from the internet to constructing some media using movies, video cutter, paint application, power point application, and quiz maker application in automotive course. The media will eventually lead to analysis capability development.

\section{B. Analytical Capability of Automo-tive Students}

Bloom's theory about learning taxono-my has been embraced by educators for years that the taxonomy of learning $\mathrm{s}$ classified 
into cognitive, psycomotoric, and affective. Each domain consist of some levels. Later on five categories of learning outcomes. The performance that may be observed as learning out-comes are considered to be made possi-ble by internally stored states of human learners, called capabilities. (Gagne et al, 1992:43). Cognitive domain is derivated to intellectual skills which enable individuals to interact with their environment in term of symbols or conceptualizations.

Later on some changes proposed by Angderson et al (2001:31) cognitive domain related to intellectual skills consist of six level, they are: 1) know-ing; 2) understanding; 3) applying; 4) analysing; 5) evaluating; and 6) creat-ing. Analytical capability is at the fourth level of cognitive domain. Most odf automotive students can only reach the third level. That when they got trouble in diagnosis of an engine prob-lems and other light vehicle problems. People come to automotive repairshop to repair their troubled vehicles which means as future automotive mechanics, automotive students need to have an analysis capability.

Troubled vehicles can be in many form. Proper troubleshooting will eliminate potential issues that aren't the real problem and point you in the right direction. There's no bigger waste of money than repairing or replacing an auto part only to find out it wasn't the problem...They can be basic trouble shooting, electrical problem, and OBD (On Board Diagnostics) Evaluation (Wright, 2014:1). Other form can be such as: 1) poor engine performance; 2) fuel consumptive; 3) oil consumptive; 4) overheating temperature; 5) poor baterray performance; 6) poor lighting system performance; 7) poor brake system performance; 8) poor power train performance; 9) running left tyre while driving; 10) excessive tolerance of steering system, and many others. In oder to be able to solve the problem, the students need to do some diagnostic based on some observation and test conducted on the vehicles. Once the data collected from the observation considered enough, the students will have to analyze the data to precisely locate or determine what actions should be taken to overcome the trouble.

\section{Some Applications to Build Instructional Media on The Basis of Movie, Power Point, and Interactive Test Creator}

There are so many applications and movies available on the internet which can be obtained for free. Some links provide animation or video which can be downloaded by the automotive students and teachers. Simply typing "How an engine car work" on address bar will lead the internet users to many sites or links provide articles, videos, movies related to the key word. The result comes up when the key word "How an engine car"typed and the enter key hit by the users is https://www.google.com/search?q=how $+\mathrm{a}$ n+engine + car + work \&ie $=$ utf- $8 \&$ oe $=$ utf$8 \& \mathrm{aq}=\mathrm{t} \& \mathrm{rls}=$ org.mozilla: id:official\&client=firefox-a\&channel $=$ fflb. Users will find more.

Let us try http://auto.howstuffworks. com/engine.htm. Users will be exposed to many links related to they key word. Automotive students and teacher can download as many as they can from the link. Various file with different exten-sion can be found and downloaded. Once some movies needed to build an instructional media acquired, the movies then, sometimes, need to be converted to other extension so that they can be compatible to work with other applications. To convert the movies, automotive students and tea-chers can download from the 
internet by typing key word "Free Video Con-verter" on the address bar and then hit the enter key. An example of free video converter is available here http://www.freemake.com/free_video_con verter/.

Another application required to build instructional media on the basis of movie is video cutter. The using of movie as an instructional media can be fun and attractive but it is not necessary to watch a movie all along during instructional process. Not only wasting time but also less effective to achieving instructional objectives. The movie need to be chopped down into shorter durations or fragments which have something to do with the instructional objectives. It will be much better when the fragments exposed to the students one after another based on the objective formulated at the lesson plan. The presence of movie fragments will likely focus the student's attention and bring their imagination deeper to visualize difficult concept required to master.

To download video cutter with many type and fitures can be downloaded from the internet. There are also some video cuttter application which can cut the video into pieces and at the same time convert the file extension into different type as the users want it to be. One type of video cutter can be found here www.vcdcutter.com. This is free software but require an internet connection when installing to the computer.

Instructional process has always to be ended by an evaluation to make sure whether the objectives formulated in the lesson plan are achieved by the students. Test, whether they are multi-ple choice, limmitted essay, or match-ing etc can be built by using many applications, one of them is wonder-share quiz maker atau http://free-

quizmaker.software.informer.com/6.1/.
Test produced by this application can be an interactive test to be integrated with various application media. There are nine events of instruction proposed by Gagne et al (1992:190) they are: 1) gaining attention; 2) informing learner of the objectives; 3) stimulating recall of prerequisite learning; 4) presenting the stimulus material; 5) providing learning guidance; 6) eliciting the per-formance; 7) providing feedback about performance correctness; 8) assessing the performance; 9) enhancing reten-tion and transfer. The eight event is facilitated by interactive test.

The last two applications require to build instructional media on the basis of movie fragment are power point and paint application of Microsoft office. These fitures are built in Microsoft office to support any paper work. Power point is very familiar for the students and the teachers. The problem is that most of automotive students and teachers haven't optimized the facilities in these fitures. Most of them can only operate power point and paint applica-tion in very simple manner which less effective to attract students attention when the instruction progres-sing. Power point is equipped with master slide fiture which can be organi-zed to create navigation buttons so that the presentation delivered will be easily handled. When some students asking to looking back some slides, the teacher can locate the slide easily simply by clicking the navigation button. Paint application create jpg file from the computer screen, even when the screen show a movie.

\section{How to Build Instructional Media on The Basis of Movie, Power Point, and Interactive Test Creator \\ 1. How to Use Video Cutter}

The first step taken is to choose some automotive movies. They can be fuel 
system, ignition system, starting sys-tem, transmision system, differential system, brake system etc. It is preferable the extension of the movie is MPG or MPEG. If the extension is different, the movies can converted to MPG or MPEG by using video converter.
VCD Cutter is a very easy to use. Free VCD Cutter can cut clips from any of your VCD in simple 3 steps. It maintains the VCD quality so you can enjoy the final clipped video without any quality loss.

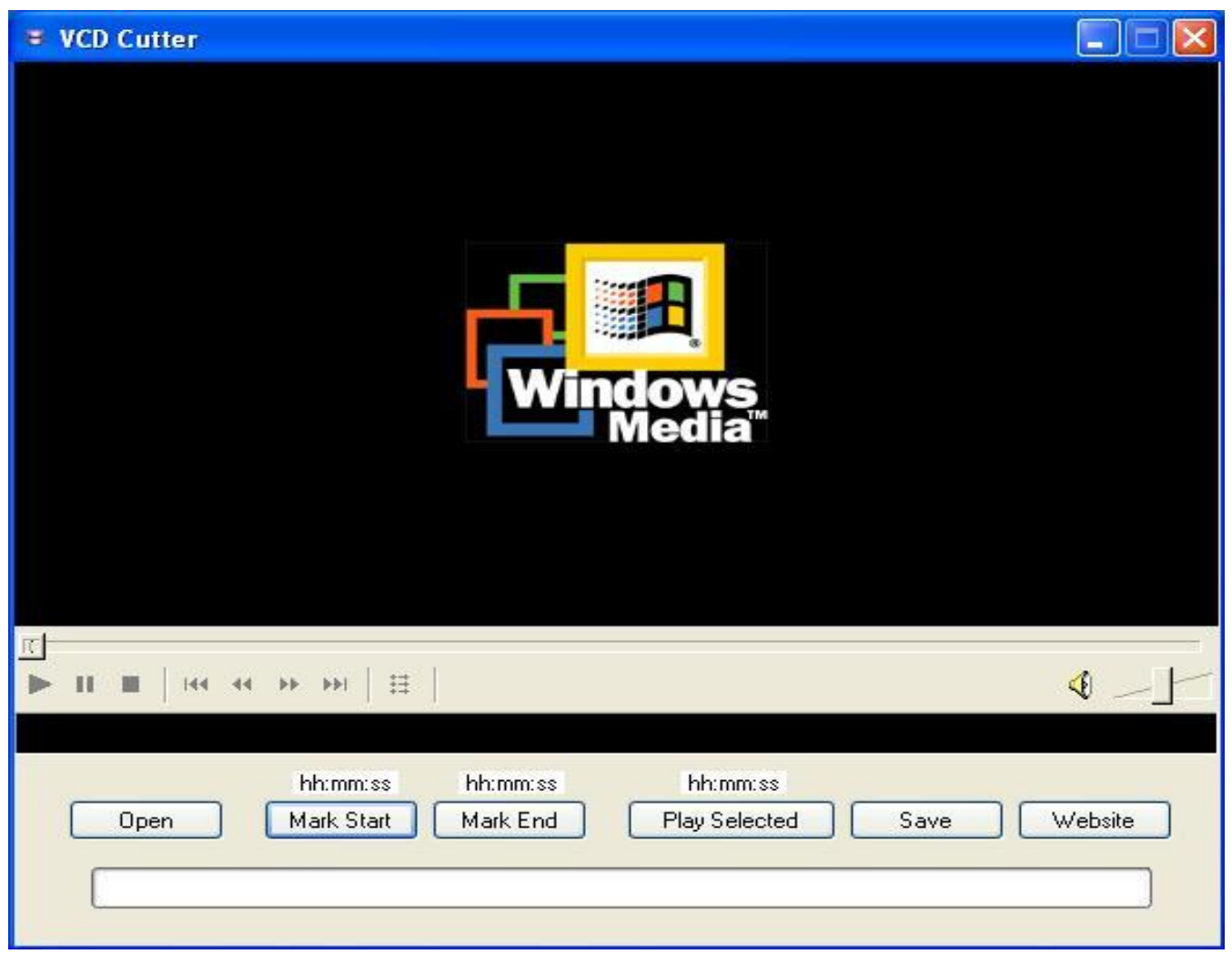

To cut clips from your VCD you need to follow simple steps: 1) Open the VCD(DAT) file by clicking open; 2) Mark start and end of VCD Clip to be made; 3) Click Save and choose the output filename; 5) Done. Automotive teachers can choose which part of the movie will be taken as part of the media organized by power point through hiperlink facility connected to the navigation button of the power point.

\section{How to Create Navigation Button,} Hiperlink, dan Slide Master of The Power Point

Automotive teachers can add buttons to their presentations. The main reason for doing so is when the teachers want a presentation that will be viewed when they're not there. For example, they may want to create an educational presentation for the students. The students can then navigate through their slides in their own time, by clicking the buttons. When the buttons are clicked they will perform an action, such as advancing to the next slide. Grouping Power Point action buttons into a navigation toolbar makes a Power Point slide show easy to navigate. The bottom of the Power Point Slide Master is a good place to add navigation. Beginning, Backward (Previous), For-ward (Next), and Ending buttons make navigation a snap, but 
teachers can include any buttons teachers want.

To create a navigation toolbar that appears on every slide, follow these steps:
1) Switch to Slide Master View

From the View tab on the Ribbon, click the Slide Master button in the Presentation Views group.

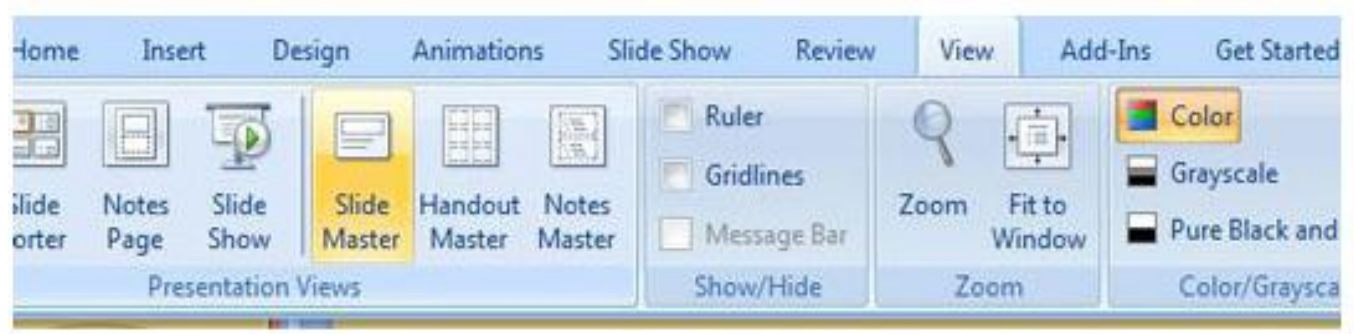

2) Create the action buttons that you want to include.

Open the Insert tab on the Ribbon and click the More button in the Shapes group to reveal the Shapes gallery. Click the button for the action button shape that you want to create. Point to where you want the upper-left corner of the button. Then click and drag to where you want the lower-right corner of the button. When you release the mouse button, the Action Settings dialog box appears.

\section{3) Return to Normal View}

Click the Normal View button or click the Normal button in the Presentation Views group on the View tab. The buttons that you created appear on every slide in your presentation. For more information automotive teachers can visit this site for free http://www.homeandlearn.co.uk/powerpoint/powerpoint p4s4.html.

In Microsoft Office PowerPoint 2007, a hyperlink is a connection from one sli-de to another slide in the same presen-tation (such as a hyperlink to a custom show) or to a slide in another presen-tation, an email address, a Web page, or a file. You can create a hyperlink from text or from an object, such as a picture, graph, shape, or WordArt. Fur-ther information about making hiperlink can be found here http://office.microsoft.com/en- us/powerpoint-help/create-a-hyperlinkHA010021479.aspx

A slide master is the top slide in a hierarchy of slides that stores information about the theme and slide layouts of a presentation, including the background, color, fonts, effects, placeholder sizes, and positioning. Every presentation contains at least one slide master. The key benefit to using slide masters is that you can make universal style changes to every slide in your presenta-tion, including ones added later to the presentation. When you use a slide master, you save time because you don't have to type the same information on more than one slide. The slide master especially comes in handy when you have extremely long presentations with lots of slides.

Because slide masters affect the look of your entire presentation, when you create and edit a slide master or corresponding layouts, you work in Slide Master view.

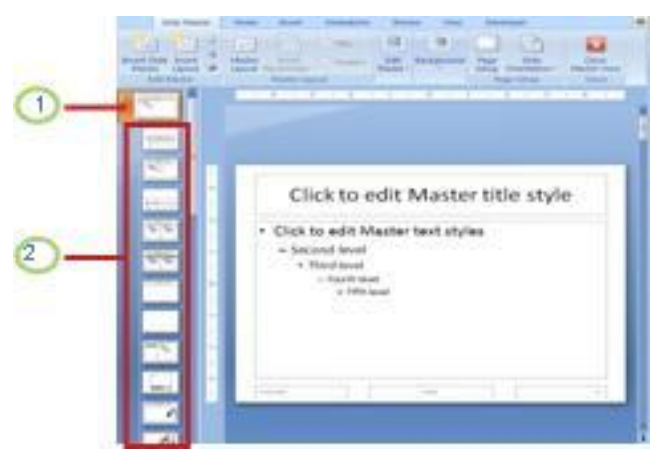


Automotive teachers can also make multiple slide masters in a presentation. When they want a presentation to contain two or more different styles or themes (such as backgrounds, colors, fonts, and effects), they need to insert a slide master for each different theme. For example, in the image that follows, there are two slide masters as you would see them in Slide Master view. Each slide master has a different theme applied to it. Each slide master owns the layouts beneath it. Any modifications or customizations made to those layouts belong to the associa-ted slide master. All presentations have a slide master, whether you modify it directly or not.

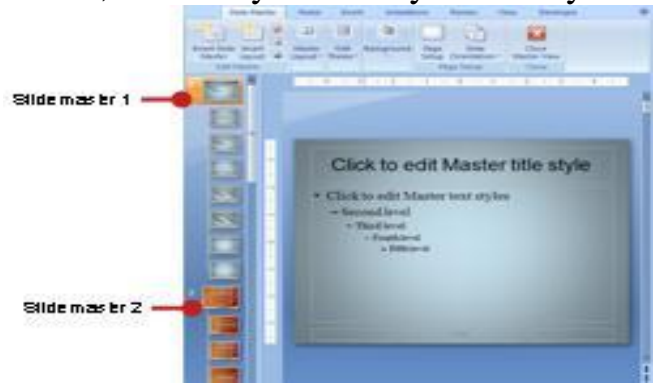

Slide master allows presentation easily connected to the students interest and request. More information about creating good slide master can be freely found here:

http://office.microsoft.com/en-

us/powerpoint-help/create-and-customizea-slide-master-HA010078011.aspx

\section{How to Build Interactive Tests}

Open wondershare quizcreator and create a new quiz. The application will lead us in.

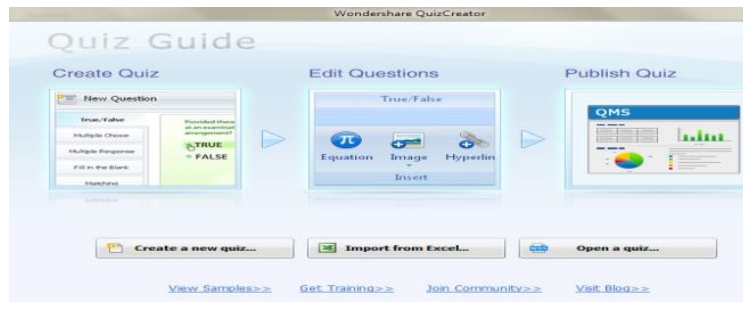

The next view will be as follows and we can chose what type of test will be.

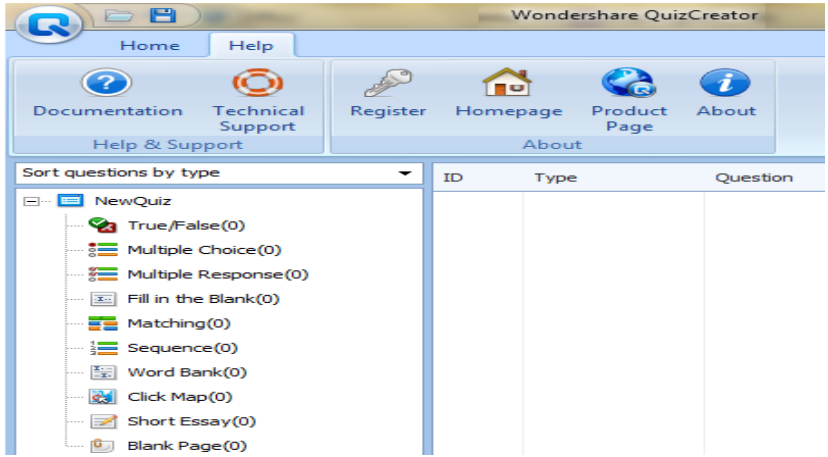

For more information about building interactive quiz, this link can be http://support.wondershare.com/quizcreat or/ visited by autmotive tea-chers as well as downloading the master.

When all movie fragments linked to the navigation button in power point organized by slide master, teacher will likely have a more applicable movie fragments, power point, and interactive testas instructional media. The buttons can be organized as many as meeting should be held in a semester. Dummy media consists of these applications is available here

http://www.4shared.com/rar/r2aCMdhYce /dummy.html

E. Various Strategy Associated with Instructional Media on The Basis of Movie, Power Point, and Interactive Test Creator

The education reformation has put students as the subject of instruction. Teachers merely act as facilitators rather than a learning resource. At this point, the instruction stands on the basis of students centered. All efforts conducted by teachers are to stimulate, promote learning. This point of view is inspired by contructivism learning theory. Various approach/model/ stra-tegies/technique can be integrated with the instructional media on the basis of movie, power point and interactive test creator. 
The main proposition of constructivism is that learning means constructing, creating, inventing, and developing our own knowledge. Others can give us information, we can find information in books, and we can get information from the media, but as important as information is-and it is very important-receiving it, getting it, and hearing it does not really necessarily equal learning (Marlowe and Page, 1998:10)

\section{Inquiry Strategy}

Inquiry learning provides opportunities for students to experience and acquire processes through which they can gather information about the world. This requires a high level of interaction among the learner, the teacher, the area of study, available resources, and the learning environment.

Students become actively involved in the learning process as they: 1) act upon their curiosity and interests; 2) develop questions; 3) think their way through controversies or dilemmas; look at problems analytically; 4) inqui-re into their preconceptions and what they already know; 5) develop, clarify, and test hypotheses; and, 6) draw infe-rences and generate possible solutions.

Six points of ativities during inqury learning absolutely can be facilitated by the using the media on the basis of movie, power point, and interactive test at the end of each presentation.

\section{Cooperative Strategy}

Dozens of studies have demonstrated that when students are allowed to work together, they experience an increase in a variety of social skills; students become more able to solve the problem which demand cooperation for a solution, better able to take the role of the other, and are generally more cooperative on a variety of measures, such as willingness to help and reward others, (Kagan, 1999:3.2)

When a slide consist of movie fragment related to a material given during instructional seems to be difficult, it will be more reasonable when the materials worked by grouping the students. Thus the presentation will guide the students among the group to get through the work.

Beside those two strategies integrated with the media on the basis of movie, power point, and interactive test, there are still many others which can be used also. They are: problem solving, con-textual teaching and learning, even almost every strategy and technique can be integrated. Just make sure the presentation goes along with the various strategies potentially used.

\section{F. Conclusion and Suggestion}

\section{Conclusion}

Sophisticated instructional media will not make any difference toward lear-ning achievement in term of analysis capability when the instruction sintax ignores nine events of instruction. It is not about the technology and the faci-lity but rather than how the automotive teacher organize the facilities to promote learning so that automotive student will be able to achieve analysis capability. The sequence of how the movie fragments arranged, presented, and then how the automotive students given some time to dig what concept lies between will stimulate and coore-late the fenomena delivered by the fragment and eventually lead to more analytical automotive learning process.

\section{Suggestion}

Some suggestions to follow are:

1) Download all applications as they are shown on the link and start to learn how to construct instruction media on 
the basis of movie, power point, and interactive test at the end of each presentation.

2) The sequence of movie fragment organized by hiperlink and slide master of powerpoint has to promote constructivism learning theory

3) Provide automotive student's worksheet to enhance their concept understanding

4) Test given at the end of meeting should be clarified to maintain their motivation that their effort is taken into account.

\section{G. Reference}

Anderson, W Lorin., Krathwohl, R David., Airasian, W Peter., Cruikshank A Kathleen., Richard E Mayer., Pintrich R Paul. Raths James., Wittrock C Merlin. 2001. A Taxonomy for Learning, Teaching and Assesing. A Revision of Bloom's Taxonomy of Educational Objectives. Abridged Edition. New York: Longman Inc.

Dewantara, Ki Hajar. 1977. Pendidikan. Majelis Luhur Persatuan Taman Siswa Yogyakarta. 371 pages.

Dick, Walter., Carey, Lou and Carey, James O. 2005. The Systematic Design of Instruction. The Sixth Edition. Boston USA: Pearson Inc. 376 pages.

Gagne, M. Robert., Briggs, Leslie J., Wager, Walter W. 1992. Principles of Ins-tructional Desin. Fourth Edition. San Diego. Harcourt Brace Jovanovich College Publishers. 359 pages.

Kagan, Spencer. 1999.Cooperative Learning.Kagan. $\quad 1160 \quad$ Calle Cordillera, San Clemente.24:13 pages.

Wright, Matthew. 2014. Trouble shooting Problems With Your Car. http://autorepair.about.com/od/trou
bleshooting/u/path_Troubleshooting.h tm accesed at 10.00 a.m. Thursday, May 1, 2014.

Marlowe, Bruce A., Page, L. Marilyn.1998.Creating and Sustaining the Constructivist Classroom.Corwin Press Inc. A sage Publication Company, Thousand Oaks, California. 181 pages.

Woolfolk, Anita. 2004. Educational Psychology. Ninth Edition. USA: Pearson Education Inc. 669 pages. 